\title{
Chemically controlled interfacial nanoparticle assembly into nanoporous gold films for
} electrochemical applications

Christiansen, Mikkel U. -B.; Seselj, Nedjeljko; Engelbrekt, Christian; Wagner, Michal; Stappen, Frederick N.; Zhang, Jingdong

Published in:

Journal of Materials Chemistry A

Link to article, DOI:

$10.1039 / \mathrm{c} 7 \mathrm{ta0} 0562 \mathrm{a}$

Publication date:

2018

Document Version

Peer reviewed version

Link back to DTU Orbit

Citation (APA):

Christiansen, M. U. -B., Seselj, N., Engelbrekt, C., Wagner, M., Stappen, F. N., \& Zhang, J. (2018). Chemically controlled interfacial nanoparticle assembly into nanoporous gold films for electrochemical applications. Journal of Materials Chemistry A, 6(2), 556-564. https://doi.org/10.1039/c7ta08562a

\section{General rights}

Copyright and moral rights for the publications made accessible in the public portal are retained by the authors and/or other copyright owners and it is a condition of accessing publications that users recognise and abide by the legal requirements associated with these rights.

- Users may download and print one copy of any publication from the public portal for the purpose of private study or research.

- You may not further distribute the material or use it for any profit-making activity or commercial gain

- You may freely distribute the URL identifying the publication in the public portal 


\section{Journal Name}

\section{ARTICLE}

\section{Chemically Controlled Interfacial Nanoparticle Assembly into Nanoporous Gold Films for Electrochemical Applications}

Received 00th January 20xx, Accepted 00th January 20xx

DOI: $10.1039 / x 0 x \times 00000 x$

www.rsc.org/

\author{
Mikkel U.-B. Christiansen, Nedjeljko Seselj, Christian Engelbrekt, Michal Wagner, Frederick N. \\ Stappen, Jingdong Zhang*
}

\begin{abstract}
Nanoporous gold (NPG) is an effective material for electrocatalysis and can be made by a dealloy method, such as etching of silver-gold alloys. Dealloyed NPG may contain residual silver that affects its catalytic performance. We report a different approach to formation of NPG at liquid/air interface, starting from gold nanoparticles (AuNPs) in an aqueous soultion, thus providing silver-free gold films. Chloroauric acid is reduced to AuNP building blocks by 2-( $\mathrm{N}$-morpholino)ethanesulfonic acid, which also acts as a protecting agent and $\mathrm{pH}$ buffer. By the addition of potassium chloride before AuNP synthesis and hydrochloric acid to the resultant AuNP solutions, we reproducibly obtain continuous gold networks. The sintered AuNPs by this method results in chemically synthesized nanoporous gold films (cNPGFs), resembling dealloyed NPG in terms of morphology and porosity, with added benefit of their control by varying the temperature, chloride concentration, ionic strength and protonation of the buffer. CNPGF formation is attributed to the destabilization of AuNPs at the air-liquid interface. The developed method generate electrochemically stable cNPGFs, up to $20 \mathrm{~cm}^{2}$ in size with an average thickness of $500 \pm 200 \mathrm{~nm}$, areal density of $50-150 \mu \mathrm{g} / \mathrm{cm}^{2}$ and porosity as high as $85 \%$. Importantly, cNPGFs can effectively catalyze both $\mathrm{CO}_{2}$ reduction and $\mathrm{CO}$ oxidation electrochemically. Thus, the developed synthetic method offers large-scale production of pure bottom-up NPGFs for multifarious electrocatalytic applications.
\end{abstract}

\section{Introduction}

Nanoporous gold (NPG) is a class of three-dimensional solid films consisting of bi-continuous networks of gold ligaments and pores with extraordinarily large specific surface areas. ${ }^{1}$ It possesses a high degree of low-coordinated surface atoms, which give rise to surface stress as well as enhanced reactivity. ${ }^{1-}$ ${ }^{4}$ NPG is electrically conductive and represents ideal electrode materials for electrochemical reactions,,$^{5-7}$ and has been demonstrated as a promising electrode material for $\mathrm{Li}_{-} \mathrm{O}_{2}$ batteries. ${ }^{8}$ Recent discoveries show that catalysts based on NPG promote selective reactions in gas-phase oxidative coupling of methanol at low temperature..$^{9,10}$ Transition metals, organic and biomolecules can be introduced on the NPG surfaces via surface engineering, providing platforms with enhanced targeted functionalities. ${ }^{11,12}$

NPG can be prepared by chemical corrosion through a "dealloying" process. It commonly involves dissolving a less noble metal such as silver from gold-silver alloy by etching in nitric acid. ${ }^{13}$ The dealloying method offers uniform NPG film as large as several hundred $\mathrm{cm}^{2}$ and broadly used in structural and functional investigations. ${ }^{3,4}$ However, residual metal such as silver can profoundly influence the electrocatalytic

Department of Chemistry, Technical University of Denmark, Kemitorvet, Building 207, 2800, Kongens Lyngby, Denmark

*Corresponding author Jingdong Zhang, email: jz@kemi.dtu.dk

Electronic Supplementary Information (ESI) available: [details of any supplementary information available should be included here]. See DOI: 10.1039/x0xx00000x performance of NPG. ${ }^{14}$ Such impurities sometimes release to the solution unexpectedly. ${ }^{1}$ Thus could cause serious side effects when they are used in bio or medical applications. This issue can be resolved with a bottom-up approach to the synthesis of NPG via constituent nanoparticles (NPs), aiming at totally preventing interference from metal impurities. In fact, gold compounds and gold nanoparticles (AuNPs) can assemble into various nano and microstructures such as mesoporous structures sponges, nanotubes, gold shells over inorganic microspheres. ${ }^{15-18}$

We demonstrate a method to chemically synthesize nanoporous gold films (cNPGFs). The synthesis is carried out under mild experimental conditions and is based on our previously developed recipe for AuNPs. ${ }^{19,20}$ Briefly, chloroauric acid was reduced to AuNPs by 2- $(\mathrm{N}-$ morpholino)ethanesulfonate (MES). Potassium chloride is used to control ionic strength and stability of the AuNPs whereas hydrochloric acid triggers sintering of AuNPs into a long-range continuous gold network, i.e. nano film. The film formation was controlled by manipulating the trapping of nanoparticles (NPs) with temperature, ionic strength and protonation of the buffer. The morphology and properties of cNPGFs were further investigated by atomic force microscopy (AFM), transmission electron microscopy (TEM), quartz crystal microbalance (QCM) and electrochemical methods. cNPGFs can effectively be transferred onto desired surface and directly subjected to various electrochemical and structural characterizations. Further, the morphology/porosity of cNPGFs can be controlled by experimental conditions including order of addition, and the type and concentration of directing reactants. Such a chemical control is highly desired, since catalytic properties are a 
"reflection" of structural characteristics. This opens the possibilities to design cNPGFs for specific tasks.

Gold nanomaterials such as AuNPs have many catalysis functions in fine chemical synthesis and electrochemical interfacial reactions, ${ }^{21-23}$ and are among the most studied catalysts for $\mathrm{CO}$ oxidation ${ }^{24}$ as well as for $\mathrm{CO}_{2}$ reduction. ${ }^{25}$ Dealloyed NPG is highly active and selective for $\mathrm{CO}$ oxidation at low temperatures. ${ }^{26,27}$ In general, $\mathrm{CO}_{2}$ decomposes efficiently via formation of $\mathrm{CO}^{28}$ Difference in stability of adsorbed intermediates in the form of $\mathrm{CO}$ and $\mathrm{COOH}$ on gold surfaces is essential for effective $\mathrm{CO}_{2}$ conversion. ${ }^{29}$ The abundance of active edge sites in NPG can enhance its catalytic efficiency. Moreover, the catalytic selectivity towards $\mathrm{CO}_{2}$ reduction over hydrogen evolution is crucial for $\mathrm{CO}_{2}$ reduction in aqueous media. Since hydrogen binds relatively weakly to gold surfaces, gold is very suitable for $\mathrm{CO}_{2}$ reduction. ${ }^{30}$ Another benefit of utilization of NPG (specifically assembled from AuNPs) in $\mathrm{CO} / \mathrm{CO}_{2}$ conversion, lies in the presence of low-coordinated $\mathrm{Au}$ sites which are crucial for $\mathrm{CO}$ oxidation. ${ }^{31}$ We observe that cNPGFs assessed in this work are highly active electrocatalysts for both $\mathrm{CO}_{2}$ reduction and $\mathrm{CO}$ oxidation. Such electrocatalytic performance of cNPGF can be attributed to immanent properties rooted on its structure.

\section{Results and discussion}

\section{Synthesis and formation of cNPGFs}

The synthesis of cNPGF starts by $\mathrm{HAuCl}_{4}$ reduction with 2-(Nmorpholino)ethanesulfonic acid (MES), forming AuNPs. Herein MES exhibits a three-fold role as buffering, reducing and AuNPs stabilizing agent. This procedure has been modified from our previously reported synthesis of MES-stabilized AuNPs. ${ }^{19,20}$ The cNPGF formation is summarized in Scheme $1 . \mathrm{KCl}$ is added before AuNPs formation to increase the ionic strength of the solution and screen the electrostatic repulsion between NPs as well as reducing the surface tension at the air-liquid interface. Consequently, AuNPs are driven to the interface due to a created energy difference $(\Delta E) .^{32}$ After AuNP formation, adsorption of NPs to the air-liquid interface is observed as an initial diffuse and incoherent film with "fluid-like" features. During the following $30 \mathrm{~min}$, an AuNP concentration gradient from the surface towards the bulk of the solution is created, due to AuNP adsorption to the air-liquid interface, and is likely a driving force for further migration of AuNPs towards the interface. The character of the film gradually changes over time, and separated patch-like structures are trapped at the interface, constantly being in motion due to turbulence in the hot solution.

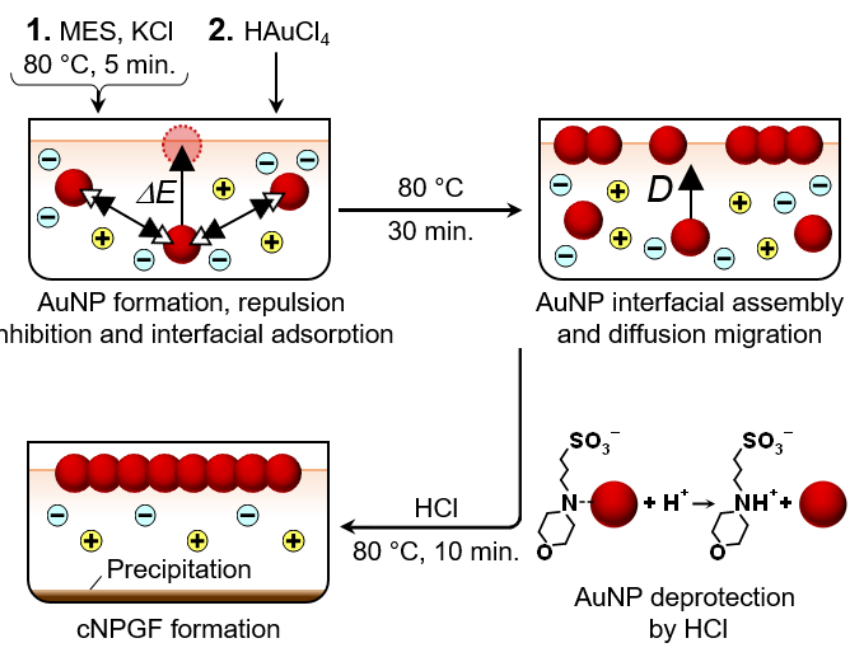

Scheme 1. Synthesis procedure of cNPGF. MES buffer and $\mathrm{KCl}$ are preheated prior to gold precursor addition. Precursor is added and MES reduces $\mathrm{HAuCl}_{4}$ to AuNPs. $\mathrm{KCl}$ increases ionic strength, decreasing both electrostatic repulsion between AuNPs and the sorption barrier for interfacial adsorption of AuNPs. Driven by the concentration gradient, bulk AuNPs diffuse towards the surface creating interfacial AuNP assemblies. Finally, the addition of $\mathrm{HCl}$ induced deprotection of AuNPs by removal of MES, resulting in structural sintering and cNPGF formation.

Finally, the addition of $\mathrm{HCl}$ effectively destabilizes the AuNPs, resulting in precipitation of particles in the bulk, and formation of sintered and robust CNPGF at the air-liquid interface. Here removing coating layers around AuNPs plays a role in formation of stable and robust cNPGFs. In fact, colloidal AuNPs could assemble at the air-water interface driven by vapor of formic acid, giving film like appearance. ${ }^{33}$ Ordered AuNP monolayers have also been formed at water-hexane interface. ${ }^{34}$ However, films prepared with these methods consisted only of individual AuNPs and a continuous porous gold film was not formed due to lack of AuNP sintering. ${ }^{33,34}$ A range of reaction parameters have been tested to optimize conditions for obtaining desirable pore sizes and area coverage with mechanical stability and reproducibility. The observations are summarized in Table S1. An optimal concentration of $\mathrm{KCl}$ was identified. High concentrations caused rapid destabilization of AuNPs precluding CNPGFs formation. CNPGF formation was enhanced when the $\mathrm{pH}$ of the MES buffer was increased from 7 to 8 , suggesting a $\mathrm{pH}$ effect on cNPG formation. It was shown previously that during formation of AuNPs with MES buffer, $\mathrm{pH}$ dropped drastically. ${ }^{20}$ We notice that the type of anion plays a role cNPGF formation. For example, potassium phosphate, as one of the most common inorganic buffers, resulted in reduced film formation, whereas presence of chloride enhanced cNPGF formation. In contrast, when perchlorate (having low affinity for metal surfaces) was used to control ionic strength, little to no cNPG formed. These observations highlight the strong and complex effects of $\mathrm{pH}, \mathrm{MES}$, anion adsorption and ionic strength on processes occurring during AuNP and cNPGF formation. 


\section{Structural characterization}

The structure of the synthesized CNPGF was mapped at different scales revealing a hierarchical porous structure. At macro-, micro- and nanoscales, the film appears porous with abundant interconnected networks, Figure 1 . Closer investigation of the nanostructure shows clearly the AuNP building blocks assembled into small NP agglomerates (Figure 2A) which further fused together to form extended networks of porous ligaments upon addition of $\mathrm{HCl}$ (Figure 2B). Similarity of nano- and microstructures are due to the 2D AuNP sintering nature at the air-liquid interface, Figure $\mathrm{S6}$.

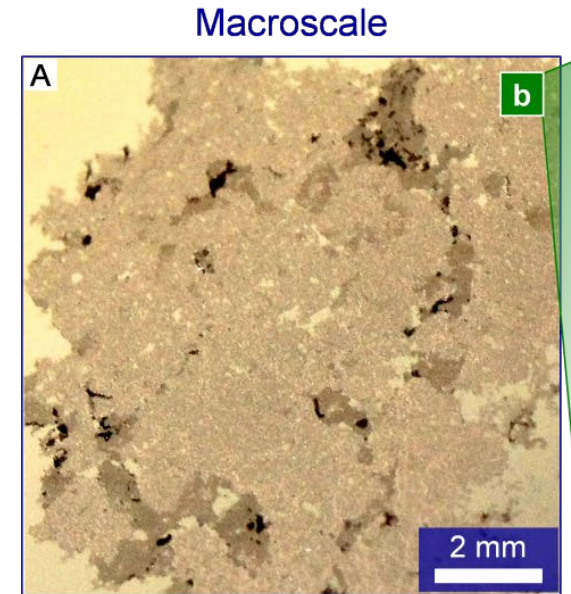

Photograph
Microscale

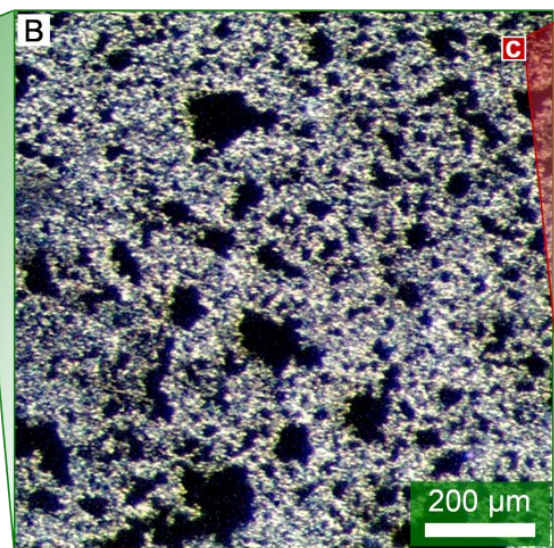

Visible light micrograph
Nanoscale

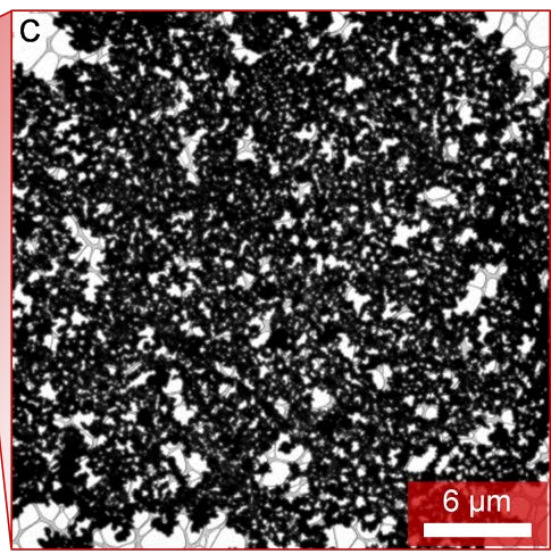

TEM image

Figure 1. Hierarchical porous structure of as-synthesized cNPGFs. (A) Photograph, (B) visible light micrograph and (C) TEM image showing porosity in three different size domains. The filled squares in (A) and (B) represent the areas of images in (B) and (C), respectively.

This is very different from the nanostructure of dealloyed NPG with continuous and smooth ligaments and pores. ${ }^{35}$ The concentrations of $\mathrm{KCl}$ and $\mathrm{HCl}$ influence strongly the film structure (Figure S5). This provides handles for tuning the morphology and porosity of the cNPGF. In general, increasing $\mathrm{HCl}$ concentrations enhances the size of the macro pores leading to web-like structures. Electron diffraction (inset of Figure 2B) confirms an fcc gold lattice with randomly oriented crystallites. The high-surface-area film displays long-range connectivity through metallic bonding with nanopores, Figure 2C-D. Since transmission electron microscopy (TEM) cannot provide direct information about film thickness, atomic-force microscopy (AFM) was employed to map the cNPGF, Figure 3. AFM displays a uniform thickness over the scanned area, Figure 3A. An average thickness of $500 \pm 200 \mathrm{~nm}$ is found with most of the film being between 300 and $600 \mathrm{~nm}$, Figure 3B-C. The nanoporosity appears as surface roughness since the AFM tip cannot penetrate into the nanopores. The roughness of cNPGF evidenced in the high magnification AFM image (Figure 3D) confirms the nanoscale porosity observed under TEM at a similar magnification (Figure 2B). The porosity of cNPGF is obtained on basis of measured values of areal density and thickness. The areal density of cNPGF was estimated via quartzcrystal microbalance (QCM) to be around $50 \mu \mathrm{g} / \mathrm{cm}^{2}$ (Figure S1), which is in consistent with $100 \pm 50 \mu \mathrm{g} / \mathrm{cm}^{2}$ measured by atomic absorption spectroscopy (AAS). Therefore, the apparent density is around $1.0-3.0 \mathrm{~g} / \mathrm{cm}^{3}$, or $5-15 \%$ of bulk gold, and a porosity of
$85-95 \% .60-80 \%$ porosity is normally found for dealloyed NPGs using $12 \mathrm{~K}$ and $9 \mathrm{~K} \mathrm{Au}-\mathrm{Ag}$ alloys. ${ }^{1}$ Close analysis of TEM images shows that the dimensions of the pores and ligaments in the cNPGF are around $25 \mathrm{~nm}$ ( $60 \%$ below $30 \mathrm{~nm}$ ) while pores up to several hundreds of $\mathrm{nm}$ are present, Figure S7 and S8.
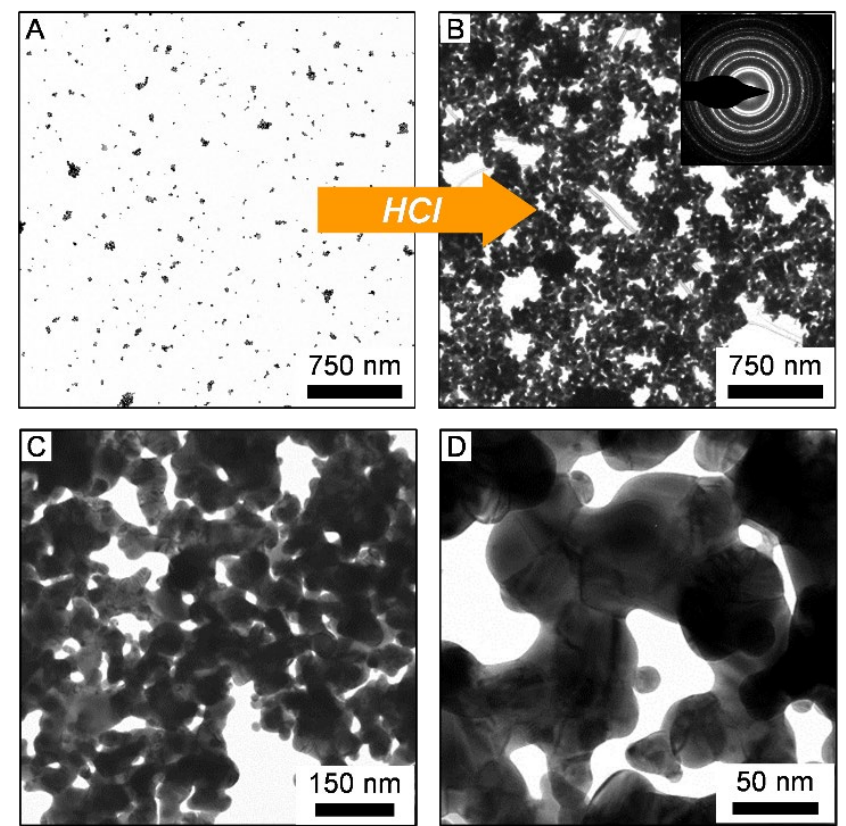

Figure 2. TEM micrographs of (A) AuNPs synthesized in $10 \mathrm{mM}$ MES ( $\mathrm{pH}$ 8.0) with $20 \mathrm{mM} \mathrm{KCl}$ before addition of $15 \mathrm{mM} \mathrm{HCl}$ and (B) same magnification of the as-synthesized NPG film. (C-D) 
Magnified view of the interconnected porous nanostructure of cNPGF.
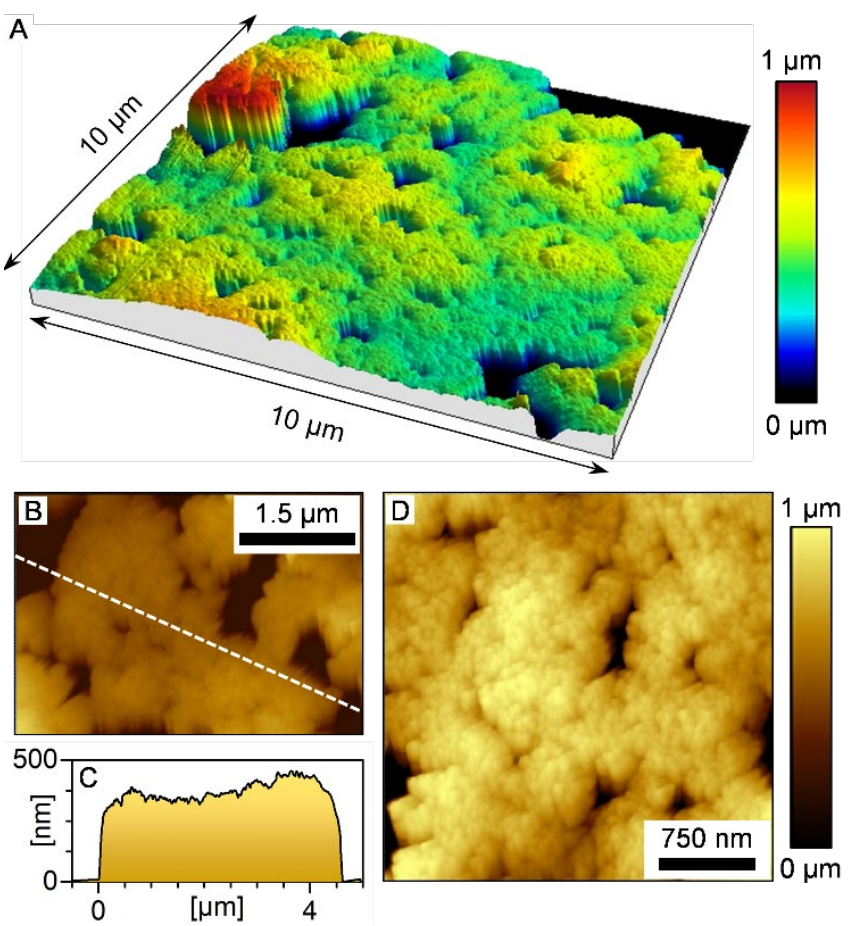

Figure 3. AFM images of cNPGF. (A) Large area $\left(10 \times 10 \mu \mathrm{m}^{2}\right) 3 D$ image showing micro scale uniform film. (B-C) Height analysis of AFM image, showing a thickness of around $400 \mathrm{~nm}$. The dashed line in (B) indicates a place of cross section plot (C). (D) High magnification of cNPGF.

The ligament thickness has been determined as $30 \pm 10 \mathrm{~nm}$, Figure S7. Interestingly, porosity is mainly in the mesoporous range and

\section{Electrochemical characterization}

Electrochemical characterization of cNPGFs was conducted using cyclic voltammetry (CV), and compared to cyclic voltammograms of AuNPs and single-crystal Au(111). Anodic and cathodic peaks around $0.25 \mathrm{~V}$ on $\mathrm{Au}(111)$ (blue curve in Figure 4A) originates from structural transitions of reconstructed $(\sqrt{ } 3 \times 22)$ to pristine $(1 \times 1)$ phases. ${ }^{36}$ The sharp, symmetric pair of peaks at $\sim 0.8 \mathrm{~V}$ is a "fingerprint" feature of $\mathrm{Au}(111)$ in sulfuric acid, due to phase transition between the disordered and ordered ( $\sqrt{ } 3 \times \sqrt{ } 7)$ R $19.1^{\circ}$ structure of adsorbed sulfate ions. ${ }^{37}$ The absence of these features in the cyclic voltammogram of AuNP (black curve) and cNPGF (red curve) suggests polycrystallinity in both materials, Figure 4A. Figure 4B shows cyclic voltammograms of cNPGF, AuNPs and Au(111) in a broad potential window. The anodic peaks from 1.05 to $1.35 \mathrm{~V}$ denote oxide layer formation at distinct low-coordinated $\mathrm{Au}$ surfaces. ${ }^{36,38,39}$ The cathodic peak at $0.85 \mathrm{~V}$ is assigned to reductive removal of these oxide layers. ${ }^{36}$
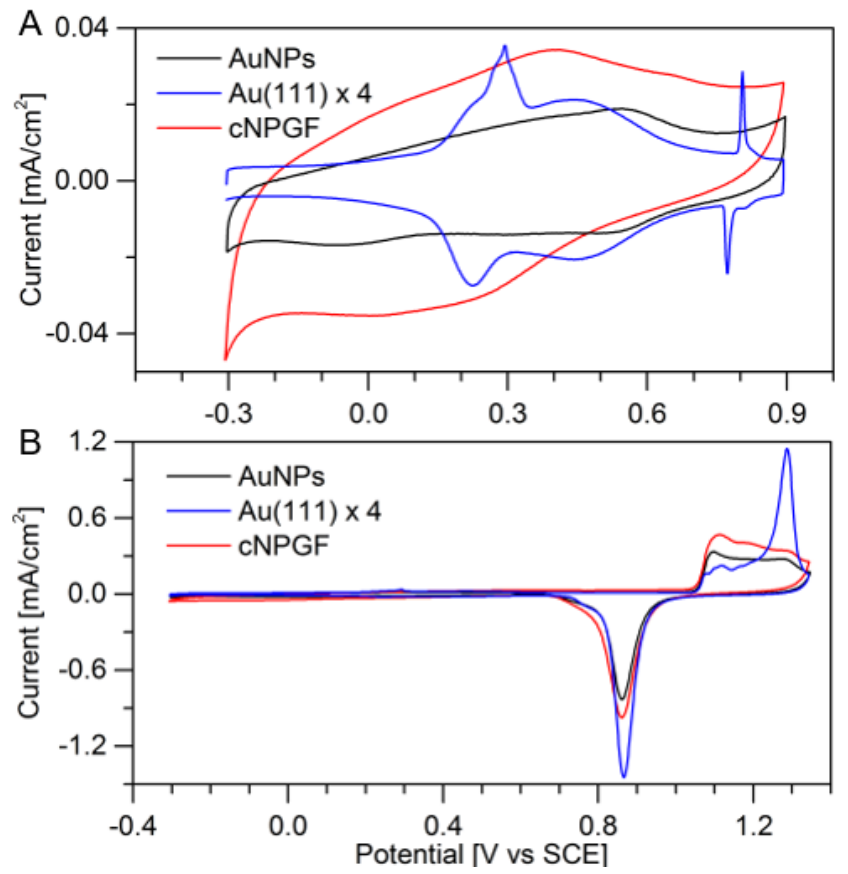

Figure 4. Cyclic voltammograms of $A u(111), A u N P s$ and $c N P G F$ in (A) narrow and (B) broad potential window. Cyclic voltammograms were recorded at $50 \mathrm{mV} / \mathrm{s}$ in $0.1 \mathrm{M} \mathrm{H}_{2} \mathrm{SO}_{4}$. The current densities related to $\mathrm{Au}(111)$ were increased four-fold for better comparison.

Electrical properties of cNPGF, and thus long-range connectivity in lateral dimensions were assessed with in situ conductance measurements performed in a four-electrode system. An interdigitated microarray Au electrode acted as WEs, Figure 5A. Applied potential values corresponding to the potential range studied in the CV experiments (Figure 4) were selected. The resultant apparent electrical conductivity values $(\sigma)$ were derived from the changes in the Ohmic current $\left(I_{\Omega}\right)$ flowing through the examined films according to the following equations:

$$
\begin{gathered}
\mathrm{I}_{\Omega}=\frac{I_{W E(1)}-I_{W E(2)}}{2} \\
\sigma=\frac{I_{\Omega} \cdot w}{\mathrm{n} \cdot \mathbf{l} \cdot \mathbf{d} \cdot \mathrm{V}}
\end{gathered}
$$

Where: $I_{W E(1)}$ and $I_{W E(2)}$ are the measured currents at corresponding WEs, $w$ is the gap between band electrodes, $n$ the number of band electrodes, I the length of band electrodes, $\mathrm{d}$ the film thickness, and $\mathrm{V}$ is the bias voltage applied between $W E(1)$ and $W E(2)$.

Almost perfect linearity and thus a clear Ohmic response was obtained up to $0.8 \mathrm{~V}$, Figure $5 \mathrm{~B}$. Above $0.8 \mathrm{~V}$, the contribution of the Faradaic current flowing between WE and CE becomes dominant and is directly related to the Au oxide formation on Au surfaces. ${ }^{36}$ However, the deviation from an Ohmic response at higher potentials is relatively small, suggesting an overall effectiveness of electronic transport in cNPGF. 
A
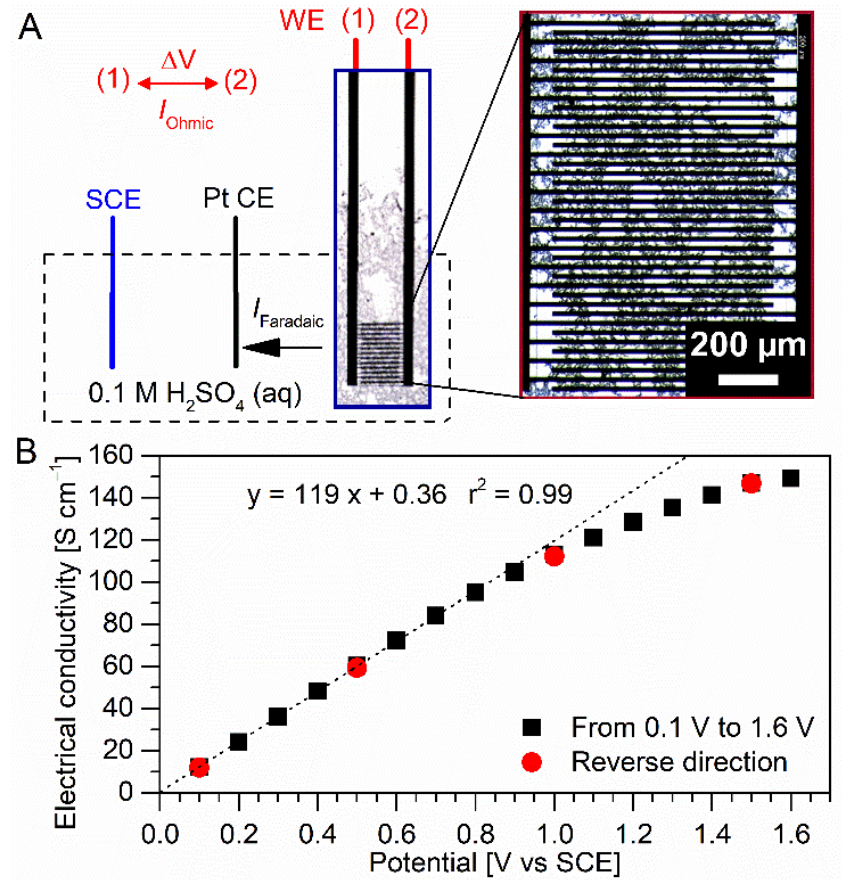

Figure 5. (A) Schematic diagram of electrochemical apparatus for in situ conductance studies in $0.1 \mathrm{M} \mathrm{H}_{2} \mathrm{SO}_{4}$. cNPGFs were uniformly deposited on interdigitated electrodes. Ohmic current was probed by keeping fixed bias between electrodes (1) and (2), during application of increasing and decreasing constant potential in the three-electrode system (saturated calomel electrode (SCE) as reference electrode (RE), Pt counter electrode (CE) and as working electrode (WE), respectively). (B) Apparent electrical conductivity vs applied potential for a typical cNPGF, together with the fitting line and corresponding equation.

Reversing the potential steps yielded the same conductance values as going from 0.1 to $1.6 \mathrm{~V}$. The onward and reverse potential cycles were repeated many times, showing no change in recorded conductance values. The latter two findings are indicative of a very stable electrochemical response of cNPGF and practically negligible hysteresis effects. Estimated values of electrical conductivity for CNPGF are in the upper semiconducting range, since the slope of approx. $120 \mathrm{~S} \mathrm{~cm}^{-1} \mathrm{~V}^{-1}$ was obtained. The resistivity values for de-alloyed NPG can be e.g. 100-fold lower. ${ }^{40}$ The reason for this discrepancy is unclear, since TEM images (see Figure 2) strongly support structural interconnectivity of cNPGFs. It might be speculated that the conductance of cNPGFs is affected by microscopic electronimpeding boundaries in ligament joints, but the assessed electrical properties of cNPGF are ample for application as chemical sensors or electrocatalysts.

\section{Electrocatalysis}

The catalytic properties of cNPGF towards $\mathrm{CO} / \mathrm{CO}_{2}$ oxidation/reduction were assessed by immobilization of the studied films on glassy carbon electrodes (GCEs) in a threeelectrode system.


Figure 6. Cyclic voltammograms of electrocatalytic (A) $\mathrm{CO}_{2}$ reduction and (B) $\mathrm{CO}$ oxidation on cNPGF. (A) Cyclic voltammograms were recorded at $20 \mathrm{mV} / \mathrm{s}$ in $0.10 \mathrm{M} \mathrm{NaHCO}_{3}$. (B) Cyclic voltammograms were recorded at $20 \mathrm{mV} / \mathrm{s}$ in $0.10 \mathrm{M}$ $\mathrm{KOH}$.

$\mathrm{CO}_{2}$ reduction was conducted in $\mathrm{CO}_{2}$-saturated $0.1 \mathrm{M} \mathrm{NaHCO}_{3}$ electrolyte, Figure $6 \mathrm{~A}$. The onset potential for the reaction was $-1.0 \mathrm{~V}$ vs SCE representing a $100 \mathrm{mV}$ reduction in overpotential compared to reports for polycrystalline $\mathrm{Au} .{ }^{41}$ The increased cathodic current densities for cNPGF in $\mathrm{CO}_{2}$ relative to $\mathrm{Ar}$, indicate a high-yielding reaction with limited $\mathrm{H}_{2}$ evolution and $88 \% \mathrm{CO}_{2}$ reduction at $-1.2 \mathrm{~V}$ Generally, gold nanostructures in $0.10 \mathrm{M} \mathrm{NaHCO}{ }_{3}$ convert $\mathrm{CO}_{2}$ mainly to $\mathrm{CO}$ with current efficiency around $87 \% .{ }^{41}$

Because of the significant porosity of CNPGFs and the proximity of a range of different active sites within the pores, prompted the study of electrochemical oxidation of $\mathrm{CO}$ to $\mathrm{CO}_{2}$. This was conducted via rotating disk electrode (RDE) experiments in COsaturated $0.10 \mathrm{M} \mathrm{KOH}$ electrolyte, Figure $6 \mathrm{~B}$.

cNPGFs exhibit characteristic features in cyclic voltammograms in Ar-saturated $0.10 \mathrm{M} \mathrm{KOH}$ electrolyte without any current increase at the rotation rate of $1600 \mathrm{rpm}$. In CO-saturated electrolyte, anodic current densities increase with rotation rate. The plateauing anodic currents in the potential region from -0.5 to $0.35 \mathrm{~V}$ are limited by $\mathrm{CO}(\mathrm{aq})$ diffusion to the $\mathrm{Au}$ active sites, which is controlled by the rotation rate. Previously reported onset values for $\mathrm{CO}$ oxidation, conducted on single-crystal $\mathrm{Au}(111)$ electrode are at $-0.61 \mathrm{~V}$ vs SCE. ${ }^{22}$ Our cNPGFs catalyzed $\mathrm{CO}$ oxidation at the onset potential of $-0.71 \mathrm{~V}$, thus resulting in $100 \mathrm{mV}$ lower overpotential. This agrees well with the results obtained for $\mathrm{CO}_{2}$ reduction, confirming the high catalytic activity for both $\mathrm{CO}_{2}$ reduction and $\mathrm{CO}$ oxidation through the abundance of active sites at the cNPGF. 


\section{Conclusions and perspectives}

Gold nanostructures such as AuNPs, gold nanorods, core-shell NPs have been developed extensively over last two decades. ${ }^{43-}$ ${ }^{46}$ In contrast to bulk gold, its nanostructures are active and their outstanding electronic, chemical and optical properties offer potential applications in molecular electronics, bio-imaging, nanomedicine, sensors, catalysts and nanotechnology. ${ }^{47-52} \mathrm{NPG}$ as a continuous solid, combines stability of bulk gold and high activity of gold nanostructures. NPG does not need any addition solid support and can be directly used as nanocatalysts. Development of dealloying method can be traced back in $1970 s^{53}$ and now is well-established for preparation of NPG with pore size (for example 30-50 $\mathrm{nm}$ ) inside of NPG, depending on compositions the alloy and etching conditions. In spite of intrigued nanostructures inside NPG, the geometric shape in macroscale is tailor-made according to the application.

Our bottom-up approach to NPG synthesis is supplemental to the well- established dealloying methods. No hash chemicals and mild experimental conditions are involved in preparation of cNPGFs. The synthesis is straight forwards and reproducible. The current recipe is based on the use of MES, which serves as reducing agent, buffer and coating agent around AuNPs. However, it could be extended to other synthetic recipes of AuNPs with a similar function of MES. The major advantages of the developed method are production of silver-free and highly porous gold films in relatively large quantities. Porosity as high as $85-95 \%$ has been achieved for the current cNPGFs, thus promising a cost-effective method. Additionally, the structure of cNPGFs is tunable through the synthesis conditions. The electrochemical properties of CNPGFs are similar to those of dealloyed NPG, reflected in good performance as electrocatalysts for $\mathrm{CO}_{2}$ reduction and $\mathrm{CO}$ oxidation. As a perspective, cNPGFs can be used as gold nanomaterials for energy conversion, chemical sensors or bio-medicine applications. Particularly, cNPGFs may make an impact on bioelectrochemistry and biofuel cells. Large surface area of cNPGFs will increase loading of microbiomolecules such as metalloproteins and enzymes and therefor increase their signals. Three-dimensional nanopores inside CNPGFs are expected to improve stability of the proteins and enhance their electrochemical activities. Immobilization of the protein molecules on cNPGFs can be achieved through surface modification or reactions as that have been welldeveloped on gold surfaces. Such strategy can be employed to develop high efficient bioanodes and biocathodes for enzymatic biofuel cells. Thanks to porous structures, cNPGFs provide a class of electrode materials for immobilization of electrochemical active bacteria for microbial fuel cells. In addition, cNPGFs can assemble on a pair of electrodes, or transparent organic / inorganic membrane or substrates, such as glass slides, offer an alternative of conducting glass indium tin oxide for spectroelectromistry and photochemistry.

\section{Experimental section}

\section{Chemicals}

Gold(III) chloride trihydrate $\left(\mathrm{HAuCl}_{4} \cdot 3 \mathrm{H}_{2} \mathrm{O}, \geq 99.5 \%\right.$, Aldrich), potassium chloride $(\mathrm{KCl}, \geq 99.5 \%$, Aldrich), 2-(Nmorpholino)ethanesulfonic acid hydrate (MES, $\geq 99.5 \%$, Aldrich), potassium hydroxide $(\mathrm{KOH}, \geq 99.99 \%$, Aldrich), hydrochloric acid $(\mathrm{HCl}, 35-37 \%$, Aldrich), potassium phosphate monobasic $\left(\mathrm{KH}_{2} \mathrm{PO}_{4}, \geq 99.995 \%\right.$, TraceSELECT ${ }^{\circ}$, Fluka), potassium phosphate dibasic $\left(\mathrm{K}_{2} \mathrm{HPO}_{4} \geq 99.999 \%\right.$, TraceSELECT ${ }^{\circ}$, Fluka), nitric acid $\left(\mathrm{HNO}_{3}, \geq 65 \%\right.$, puriss. p.a., Fluka), potassium perchlorate $\left(\mathrm{KClO}_{4}, 99.99 \%\right.$, Aldrich), perchloric acid $\left(\mathrm{HClO}_{4}\right.$, $70 \%$ in water, $99.999 \%$ trace metal basis, Aldrich), sodium bicarbonate $\left(\mathrm{NaHCO}_{3},>99.7 \%\right.$, Fluka), and sulfuric acid $\left(\mathrm{H}_{2} \mathrm{SO}_{4}, \geq 95 \%\right.$, TraceSELECT ${ }^{\circ}$, Fluka) were used without further purification. Aqua regia was prepared by mixing nitric and hydrochloric acids in 1:3 ratio. Aqueous solutions were prepared with Millipore water (18.2 $\mathrm{M} \Omega \mathrm{cm}$, Sartorius). Ar (5.0 $\mathrm{N}, A G A A / S)$ and $H_{2}(5.0 \mathrm{~N}, A G A$ GAS $A B)$ were used for electrochemical measurements. Electrocatalytic experiments were performed with $\mathrm{CO}(4.7 \mathrm{~N}$, Linde $\mathrm{AG})$ and $\mathrm{CO}_{2}(5.2 \mathrm{~N}, \mathrm{AGA}$ GAS AB).

\section{Synthesis of cNPGFs}

In a standard synthesis, $12 \mathrm{~mL}$ of ultrapure water, $4 \mathrm{~mL} 100 \mathrm{mM}$ $\mathrm{KCl}$ and $2 \mathrm{~mL} 100 \mathrm{mM}$ MES ( $\mathrm{pH}$ 8.0) were mixed in a $\varphi=50 \mathrm{~mm}$ beaker, which was placed in an oil bath for pre-heating at $80^{\circ} \mathrm{C}$ for $5 \mathrm{~min}$. Then, $2 \mathrm{~mL} 20 \mathrm{mM} \mathrm{HAuCl}_{4}$ was added while the beaker was kept at $80^{\circ} \mathrm{C}$. AuNPs were formed almost instantly and the reaction was left to proceed for $30 \mathrm{~min}$. At this point, an oily "pre-film" consisting of individual microscopic gold assemblies at the air-liquid interface had formed. Upon addition of $75 \mu \mathrm{L}$ of $4.0 \mathrm{M} \mathrm{HCl}$, the cNPGF morphology started to change into a single coherent piece of film. This process was allowed to occur for $10 \mathrm{~min}$ at $80^{\circ} \mathrm{C}$ after which the beaker was removed from the oil bath. After the synthesis, it is important to separate the film from the AuNP solution to stop the process completely. The reaction mixture was partly removed from underneath the cNPGF by pipette followed by addition of ultrapure water. This was repeated twice to pre-clean the solution. Then, the beaker was filled to the brim with water, and the whole beaker was immersed carefully into a large glass bath with ultrapure water, taking care not to break the CNPGF in the process. From this container, the cNPGF was transferred to a $3 \mathrm{~L}$ beaker filled with ultrapure water with a clean plastic spoon for final cleaning through diffusion and storage.

\section{Instrumentation and methodology}

\section{Microscopy techniques}

Visible light micrographs were recorded on a Leica M205C from Leica Microsystems (Wetzlar, Germany). Transmission electron micrographs were obtained on a Tecnai G2 T20 from FEI Company (Hillsboro OR, USA) at $200 \mathrm{kV}$ accelerating voltage. TEM samples were loaded on pure or lacey carbon coated copper grids from Ted Pella (Redding CA, USA) by picking up the floating films from below the water surface with the grids fixed in a tweezer. The micrographs were analyzed with ImageJ $1.50 \mathrm{i}$ 
software. ${ }^{54}$ Atomic force microscopy (AFM) (a 5500 SPM system, Keysight Technologies, Santa Rosa CA, USA) controlled by PicoView 1.20 software was used in tapping mode. AFM samples were prepared by picking up the floating cNPGFs with freshly cleaved mica sheets and drying at room temperature. AFM data were analyzed with Picolmage 6.2.

\section{Electrochemical experiments}

The stationary glassy carbon electrode (GCE, $\varphi=4.0 \mathrm{~mm}, \mathrm{~A}=$ $\left.0.1256 \mathrm{~cm}^{2}\right)$ and rotating disk electrode (RDE, $\varphi=5.61 \mathrm{~mm}, A=$ $0.2472 \mathrm{~cm}^{2}$ ) were wet-polished by sand paper (grit roughness 2000, followed by 4000 ) for $10 \mathrm{~min}$ by hand. Further polishing with alumina slurry (particle sizes of $1.0,0.3$ and $0.05 \mu \mathrm{m}$ in diameter), was done on a polishing machine (300 rpm, $5 \mathrm{~min}$ per cycle) providing a mirror-like electrode surface finish. The electrodes were sonicated for $30 \mathrm{~min}$ in total with intermittent water exchange. The CNPGF immobilization was performed by submersion of the electrode in a $2 \mathrm{~L}$ beaker containing ultrapure water and floating CNPGF, followed by a rapid upward movement of the electrode to effectively entrap the film on the electrode surface. The covered electrodes were dried at room temperature in the fume hood. Afterwards, excess film was removed by a micropipette tip to match the electrode surface. Finally, the immobilized cNPGF was protected by drop casting 5 $\mu \mathrm{L}$ of $0.05 \mathrm{wt} \%$ Nafion solution (dissolved in ethanol) and drying at $60{ }^{\circ} \mathrm{C}$ for 20 minutes. As-prepared electrodes were imaged with an optical microscope, and cNPGF areas integrated to precisely report the material activity, Figure S3.

All electrochemical measurements were performed in Faraday cage at room temperature $\left(20 \pm 2^{\circ} \mathrm{C}\right)$ using Autolab PGSTAT 12 (Metrohm, The Netherlands) controlled by the general purpose electrochemical system (GPES) or NOVA 1.11 software. All of the glassware was boiled in $15 \% \mathrm{HNO}_{3}$ for 20 minutes, copiously washed with ultrapure water and sonicated for 30 minutes twice, prior to each experiment. Electrochemistry measurements were performed in $0.1 \mathrm{M} \mathrm{H}_{2} \mathrm{SO}_{4}(\mathrm{pH}=1.0), 0.1$ $\mathrm{M} \mathrm{NaHCO}_{3}(\mathrm{pH}=8.5)$ or $0.1 \mathrm{M} \mathrm{KOH}(\mathrm{pH}=13.0)$ with a threeelectrode system consisting of the GCE/RDE as a working electrode (WE), home-made reversible hydrogen electrode (RHE) ${ }^{55}$ as a reference electrode (RE) and a platinum coiled wire with a large surface area as a counter electrode (CE). The CE was cleaned in a hydrogen flame followed by washing with ultrapure water at least 3 times. A fresh RHE filled with the same supporting electrolyte as in cell for measuring was prepared prior to each experiment. The potential of the RHE was measured vs saturated calomel electrode (SCE) after each experiment and all results are reported versus SCE. Purging the

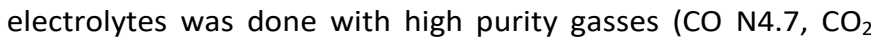
N5.2 and Ar N5.0). Ar degassing was performed for minimum 20 min. Saturation with $\mathrm{CO}$ and $\mathrm{CO}_{2}$ was conducted for bubbling the solution for more than 50 minutes. All the immobilized cNPGF were activated in $\mathrm{Ar}$ purged $0.10 \mathrm{M} \mathrm{H}_{2} \mathrm{SO}_{4}$ by cyclic voltammetry for a minimum of 40 cycles at $100 \mathrm{mV} / \mathrm{s}$ until stabile profiles were obtained.

In situ conductance studies of cNPGF were made on interdigitated Au microarray electrodes, obtained from MicruX
Technologies (Oviedo, Spain). The distance between each band electrodes (1.1 mm long, 40 in total) was $20 \mu \mathrm{m}$. Deposited cNPGFs were rinsed with water and dried at ca. $60{ }^{\circ} \mathrm{C}$ for $1 \mathrm{~h}$. Monitoring of the changes in conductance upon increasing potential was realized by application of constant bias of $0.5 \mathrm{mV}$ between electrodes. The measurements in $0.1 \mathrm{M} \mathrm{H}_{2} \mathrm{SO}_{4}$ (aq) electrolyte were conducted utilizing Autolab PGSTAT 12. The control of applied potentials and recording of obtained currents were done in bipotentiostat mode. Further details on the in situ conductance measurement set-up and calculations have been reported previously. ${ }^{56}$

\section{Areal density estimation}

The areal density of cNPGFs was investigated by quartz-crystal microbalance (QCM) measurements on a QCM200 instrument (SRS Stanford Research Instruments, USA) utilizing the Sauerbrey equation. ${ }^{57}$ The used QCM sensors were coated with $\mathrm{Au}$ (surface area $=1.327 \mathrm{~cm}^{2}$ ), with sensitivity of $56.6 \mathrm{~Hz} \mathrm{\mu g}^{-1}$ $\mathrm{cm}^{2}$, and oscillating at around $5 \mathrm{MHz}$. Atomic adsorption spectroscopy (AAS) was used as a secondary method to determine the areal density of CNPGF, and carried out on a Perkin Elmer Atomic Absorption Spectrometer 4100 and a light source from S\&J Juniper \& Co (Au, $242.8 \mathrm{~nm})$. The samples were quantified by recording a standard curve alongside the samples. Triple determination was performed for all data points. Samples were prepared by transfer of floating CNPGF from water bath onto a glass slide or GCE. The GCE area is well-defined and the $\mathrm{Au}$ covered glass slide area was defined by analyzing micrographs of the slides with Image J software. The CNPGF was dissolved by keeping the specimens in aqua regia for overnight. The glass slide or electrode was removed from the vial and the solution was heated to dryness. The solid remnants were dissolved in $5 \mathrm{~mL}$ of 10 vol\% $\mathrm{HCl}$ as recommended by Perkin Elmer to use for Au AAS on their instrument. ${ }^{58}$

\section{Conflicts of interest}

There are no conflicts to declare. The manuscript was written through contributions of all authors. All authors have given approval to the final version of the manuscript.

\section{Acknowledgements}

Finance support from Lundbeck foundation (R141-2013-13273), Danish Council for Independent Research (DFF - 1335-00330), Carlsberg foundation (2012_01_0520) to JZ, the Danish Council for Independent Research (DFF 5054-00107) to CE, and FP7 Marie Curie (COFUND Postdoc DTU 609405) to MW is acknowledged.

\section{References}


1 Wittstock, A.; Biener, J.; Erlebacher, J.; Bäumer, M., Eds. Book 'Nanoporous Gold: From an Ancient Technology to a HighTech Material'; The Royal Society of Chemistry, 2012.

2 Chapman, C. A. R.; Chen, H.; Stamou, M.; Biener, J.; Biener, M. M.; Lein, P. J.; Seker, E. Nanoporous Gold as a Neural Interface Coating: Effects of Topography, Surface Chemistry, and Feature Size. ACS Appl Mater Interfaces 2015, 7, 7093-7100.

3 Fujita, T.; Guan, P.; McKenna, K.; Lang, X.; Hirata, A.; Zhang, L.; Tokunaga, T.; Arai, S.; Yamamoto, Y.; Tanaka, N.; Ishikawa, Y.; Asao, N.; Erlebacher, J.; Chen, M. Atomic Origins of High Catalytic Activity of Nanoporous Gold, Nat. Mater., 2012, 11 $775-780$.

4 Déronzier, T.; Morfin, F.; Lomello M.; Rousset, J. Catalysis on Nanoporous Gold-Silver Systems: Synergistic Effects toward Oxidation Reactions and Influence of the Surface Composition, J. of Catalysis, 2014, 311, 221-229.

5 Wang, R.; Liu, J.; Liu, P.; Bi, X.; Yan, X.; Wang, W.; Ge, X.; Chen, M.; Ding, Y. Dispersing Pt Atoms onto Nanoporous Gold for High Performance Direct Formic Acid Fuel Cells. Chem. Sci. 2014, 5, 403-409.

6 Collinson, M. M. Nanoporous Gold Electrodes and Their Applications in Analytical Chemistry. ISRN Anal. Chem. 2013, 2013, 1-21.

7 Snyder, J.; Fujita, T.; Chen, M. W.; Erlebacher, J. Oxygen Reduction in Nanoporous Metal-Ionic Liquid Composite Electrocatalysts, Nat. Mater., 2010, 9, 904-907.

8 Peng, Z.; Freunberger, S. A.; Chen Y.; Bruce, P. G. A Reversible and Higher-Rate Li-O2 Battery, Science, 2012, 337, 563-566.

9 Wittstock, A.; Zielasek, V.; Biener, J.; Friend, C. M.; Bäumer, M. Nanoporous Gold Catalysts for Selective Gas-Phase Oxidative Coupling of Methanol at Low Temperature. Science, 2010, 327, 319-323.

10 Haibing, X.; Ran, Y.; Houshen, L.; Xutang, T.; Dayang, W. Freestanding monolayered nanoporous gold films with high electrocatalytic activity via interfacial self-assembly and overgrowth, J. Mater. Chem. A, 2013,1, 4678-4684.

11 Li, J.; Yin, H.; Li, X.; Okunishi, E.; Shen, Y.; He, J.; Tang, Z.; Wang, W.; Yücelen, E.; Li, C.; Gong, Y.; Gu, Lin, Miao, S.; Liu, L.; Lou, J.; Ding, Y. Surface evolution of a Pt-Pd-Au electrocatalyst for stable oxygen reduction, Nature Energy, 2017, 2, 17111.

12 Xiao, X.; Ulstrup, J.; Li, H.; Wang, M.; Zhang, J.; Si, P. Nanoporous Gold Assembly of Glucose Oxidase for Electrochemical Biosensing, Electrochim. Acta, 2014, 130, 559-567.

13 Oppenheim, I. C.; Trevor, D. J.; Chidsey, C. E. D.; Trevor P. L.; Sieradzki, K. In situ Scanning Tunnelling Microscopy of Corrosion of Silver-Gold Alloys, Science, 1991, 254, 687-689.

14 Biener, J.; Biener, M. M.; Madix, R. J.; Friend, C. M. Nanoporous Gold: Understanding the Origin of the Reactivity of a 21st Century Catalyst Made by Pre-Columbian Technology. ACS Catal. 2015, 5, 6263-6270.

15 Zhang, Y. X.; Zeng, H. C., Surfactant-Mediated Self-Assembly of Au Nanoparticles and Their Related Conversion to Complex Mesoporous Structures, Langmuir, 2008, 24, 3740-3746.

$16 \mathrm{Yu}$, B.; Zhang, X.; Zeng, H. C., Gold (I)- Alkanethiolate Nanotubes, Adv. Mater. 2009, 21, 4962-4965.

17 Zhang, Y. X.; Zeng, H. C., Gold Sponges Prepared via Hydrothermally Activated Self-Assembly of Au Nanoparticles, J. Phys. Chem. C, 2010, 111, 6970-6975.

18 Li, Q.; Hao, X.; Guo, X.; Dong, F.; Zhang, Y., Controlled deposition of $\mathrm{Au}$ on $(\mathrm{BiO})_{2} \mathrm{CO}_{3}$ microspheres: the size and content of $\mathrm{Au}$ nanoparticles matter, Dalt. Trans. 2015, 44 8805-8811.

19 Engelbrekt, C.; Sørensen, K. H.; Zhang, J.; Welinder, A. C.; Jensen, P. S.; Ulstrup, J. Green Synthesis of Gold Nanoparticles with Starch - Glucose and Application in Bioelectrochemistry. J. Mater. Chem. 2009, 19, 7839-7847.
20 Engelbrekt, C.; Jensen, P. S.; Sørensen, K. H.; Ulstrup, J.; Zhang, J. Complexity of Gold Nanoparticle Formation Disclosed by Dynamics Study. J. Phys. Chem. C 2013, 117, 11818-11828.

21 Hashmi A. S. K.; Hutchings, G. J. Gold Catalysis, Angew. Chem. Int. Ed., 2006, 45, 7896-7936.

22 Zhang, Y.; Cui, X.; Shi F.; Deng, Y. Nano-Gold Catalysis in Fine Chemical Synthesis, Chem. Rev., 2012, 112, 2467-2505.

23 Burke, L. D. Scope for New Applications for Gold Arising from the Electrocatalytic Behavior of its Metastable Surface States, Gold Bulletin, 2004, 37, 125-135.

24 Guo, L.; Du, P.; Fu, X.; Ma, C.; Zeng, J.; Si, R.; Huang, Y.; Jia, C.; Zhang, Y.; Yan, C. Contributions of Distinct Gold Species to Catalytic Reactivity for Carbon Monoxide Oxidation. Nat. Communications, 2016, 7, 13481.

25 Back, S.; Yeom, M. S.; Jung, Y. Active Sites of $\mathrm{Au}$ and $\mathrm{Ag}$ Nanoparticle Catalysts for $\mathrm{CO} 2$ Electroreduction to CO. ACS Catal. 2015, 5, 5089-5096.

26 Li, D.; Zhu, Y.; Wang, H.; Ding, Y. Nanoporous Gold as an Active Low Temperature Catalyst toward CO Oxidation in HydrogenRich Stream. Sci. Rep. 2013, 3, 1-7.

27 Kameoka, S.; Tanabe, T.; Miyamoto, K.; Tsai, A. P. Insights into the Dominant Factors of Porous Gold for CO Oxidation Insights into the Dominant Factors of Porous Gold for CO Oxidation. J. Chem. Phys. 2017, 34703.

28 Noda, H.; Ikeda, S.; Yamamoto, A.; Einaga, H.; Ito, K. Kinetics of Electrochemical Reduction of Carbon Dioxide on a Gold Electrode in Phosphate Buffer Solutions. Bull. Chem. Soc. Jpn. 1995, 68, 1889-1895.

29 Hansen, H. A.; Varley, J. B.; Peterson, A. A.; Nørskov, J. K. Understanding Trends in the Electrocatalytic Activity of Metals and Enzymes for $\mathrm{CO} 2$ Reduction to CO. J. Phys. Chem. Lett. 2013, 4, 388-392.

30 Nørskov, J. K.; Bligaard, T.; Logadottir; Kitchin, J. R.; Chen, J. G.; Pandelov, S.; Stimming, U. Trends in the Exchange Current for Hydrogen Evolution. J. Electrochem. Soc. 2005, 152, 2326

31 Remediakis, I. N.; Lopez, N.; Nørskov, J. K. CO Oxidation on Gold Nanoparticles: Theoretical Studies. Appl. Catal. A Gen. 2005, 291, 13-20.

32 Popp, N.; Kutuzov, S.; Böker, A. Complex Macromolecular Systems II; Müller, A. H. E.; Schmidt, H.-W., Eds.; Springer, 2010.

33 Zhang, Y.; Xu, Y.; Xia, Y.; Huang, W.; Liu, F.; Yang, Y.; Li, Z. A Novel Strategy to Assemble Colloidal Gold Nanoparticles at the Water-air Interface by the Vapor of Formic Acid, Journal of Colloid and Interface Science, 2011, 359, 536-541.

34 Park, Y.; Yoo, S.; Park, S. Assembly of Highly Ordered Nanoparticle Monolayers at a Water/Hexane Interface, Langmuir, 2007, 23, 10505-10510.

35 Fujita, T.; Tokunaga, T.; Zhang, L.; Li, D.; Chen, L.; Arai, S.; Yamamoto, Y.; Hirata, A.; Tanaka, N.; Ding Y.; Chen, M. Atomic Observation of Catalysis - Induced Nanopore Coarsening of Nanoporous Gold, Nano Lett., 2014, 14, 1172-1177.

36 Hamelin, A. Cyclic Voltammetry at Gold Single-Crystal Surfaces. Part 1. Behaviour at Low-Index Faces. J. Electroanal. Chem. 1996, 407, 1-11.

37 Soldo-Olivier, Y.; De Santis, M.; Liang, W.; Sibert, E. Growth Mechanisms of Pd Nanofilms Electrodeposited onto Au(111): An in Situ Grazing Incidence X-Ray Diffraction Study. Phys. Chem. Chem. Phys. 2016, 18, 2830-2839.

38 Hamelin, A.; Martins, A. M. Cyclic Voltammetry at Gold Single-Crystal Surfaces. Part 2. Behaviour of High-Index Faces. J. Electroanal. Chem. 1996, 407, 13-21.

39 Merrill, D. R.; Stefan, I. C.; Scherson, D. A.; Mortimer, J. T. Electrochemistry of Gold in Aqueous Sulfuric Acid Solutions under Neural Stimulation Conditions. J. Electrochem. Soc. 2005, 152, E212-E221. 
40 Hakamada, M.; Kato, N.; Miyazawa, N.; Mabuchi, M. WaterAdsorption Effect on Electrical Resistivity of Nanoporous Gold. Scr. Mater. 2016, 123, 30-33.

41 Lates, V.; Falch, A.; Jordaan, A.; Peach, R.; Kriek, R. J. An Electrochemical Study of Carbon Dioxide Electroreduction on Gold-Based Nanoparticle Catalysts. Electrochim. Acta 2014 128, 75-84.

42 Gallagher, M. E.; Blizanac, B. B.; Lucas, C. A.; Ross, P. N. Marković, N. M. Structure Sensitivity of CO Oxidation on Gold Single Crystal Surfaces in Alkaline Solution: Surface X-Ray Scattering and Rotating Disk Measurements. Surf. Sci. 2005, 582, 215-226.

43 Daniel, M. C.; Astruc, D. Gold Nanoparticles: Assembly, Supramolecular Chemistry, Quantum-Size-Related Properties, and Applications Toward Biology, Catalysis, and Nanotechnology. Chem. Rev. 2004, 104, 293-346.

44 Alkilany, A. M.; Lohse, S. E.; Murphy, C. J. The Gold Standard Gold Nanoparticle Libraries to Understand the Nano-Bio Interface, Accounts of Chemical Research, 2013, 46, 650-661.

45 Joseph, V.; Engelbrekt, C.; Zhang, J.; Gernert, U.; Ulstrup J.; Kneipp, J. Characterizing the Kinetics of Nanoparticle Catalyzed Reactions by SurfaceEnhanced Raman Scattering, Angewandte Chemie (International Edition), 2012, 51, 75927596.

46 Chaudhuri, G. R.; Paria, S.; Core/Shell Nanoparticles: Classes, Properties, Synthesis, Mechanisms, Characterization, and Applications, Chem. Rev., 2012, 112, 2373-2433.

47 Gür, F. N.; Schwarz, F. W.; Ye, J.; Diez, S.; Schmidt, T. L. Toward Self-Assembled Plasmonic Devices: High-Yield Arrangement of Gold Nanoparticles on DNA Origami Templates. ACS Nano 2016, 10, 5374-5382.

48 Schreiber, R.; Santiago, I.; Ardavan, A.; Turberfield, A. J. Ordering Gold Nanoparticles with DNA Origami Nanoflowers. ACS Nano 2016, 10, 7303-7306.

49 Song, J.; Yang, X.; Yang, Z.; Lin, L.; Liu, Y.; Zhou, Z.; Shen, Z.; Yu G.; Dai, Y.; Jacobson, O.; et al. Rational Design of Branched
Nanoporous Gold Nanoshells with Enhanced Physico-Optical Properties for Optical Imaging and Cancer Therapy. ACS Nano 2017, 11, 6102-6113.

50 Rao, W.; Wang, D.; Kups, T.; Baradács, E.; Parditka, B.; Erdélyi, Z.; Schaaf, P. Nanoporous Gold Nanoparticles and Au/Al2O3 Hybrid Nanoparticles with Large Tunability of Plasmonic Properties. ACS Appl. Mater. Interfaces 2017, 9, 6273-6281.

51 Zugic, B.; Wang, L.; Heine, C.; Zakharov, D. N.; Lechner, B. A J.; Stach, E. A.; Biener, J.; Salmeron, M.; Madix, R. J.; Friend, C. M. Dynamic Restructuring Drives Catalytic Activity on Nanoporous Gold-Silver Alloy Catalysts. Nat. Mater. 2017, 16, 558-564.

52 Katz, E.; Willner, I.; Integrated Nanoparticle-Biomolecule Hybrid Systems: Synthesis, Properties, and Application, Angew. Chem. Int. Ed., 2004, 43, 6042-6108.

53 Forty, A. J. Corrosion Micromorphology of Noble Metal Alloys and Depletion Gilding, Nature, 282, 597-598.

54 Schneider, C. A.; Rasband, W. S.; Eliceiri, K. W. NIH Image to ImageJ: 25 years of image analysis Nat. Methods 2012, 9 (7) 671-675.

55 Nishizawa, M.; Uchida, I. Microelectrode-Based Characterization Systems for Advanced Materials in Battery and Sensor Applications. 1999, 44, 3629-3637.

56 Zhang, J.; Chi, Q.; Nielsen, J. U.; Friis, E. P.; Andersen, J. E. T. Ulstrup, J. Two-Dimensional Cysteine and Cystine Cluster Networks on $\mathrm{Au}(111)$ Disclosed by Electrochemistry and in situ STM, Langmuir, 2000, 16, 7229-7237.

57 Sauerbrey, G. Verwendung von Schwingquarzen Zur Wägung Dünner Schichten Und Zur Mikrowägung. Zeitschrift für Phys. 1959, 155, 206-222.

58 Analytical Methods for Atomic Absorption Spectrometry Perkin-Elmer Corporation, 1994. 


\section{Journal Name}

\section{ARTICLE}

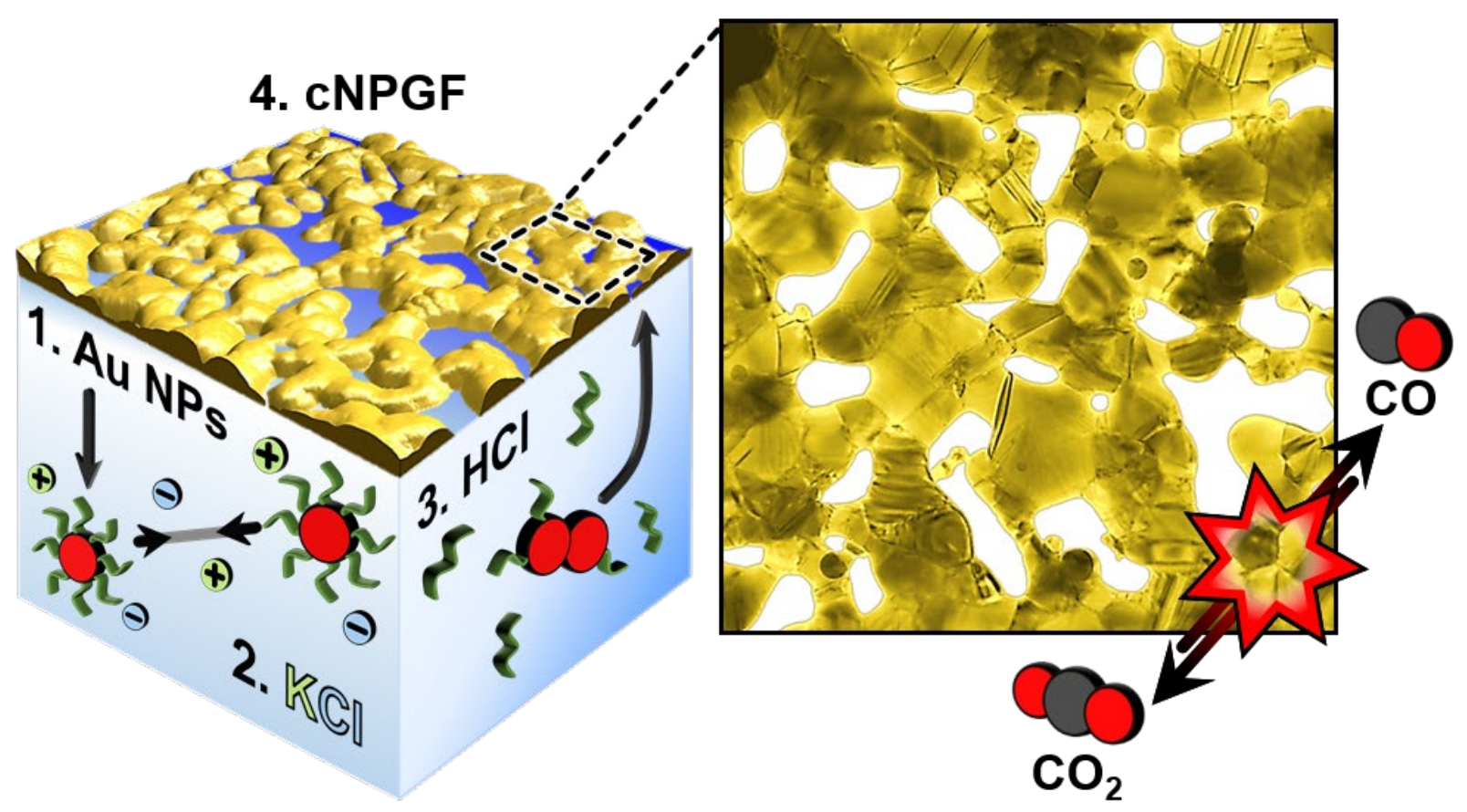

\section{Supporting information}






Figure S1. Typical massograms obtained during recording of QCM signals of bare (blue line) and cNPGF-coated (red line) sensors in air. The difference in frequency of oscillating sensors yields apparent areal density of deposited film.

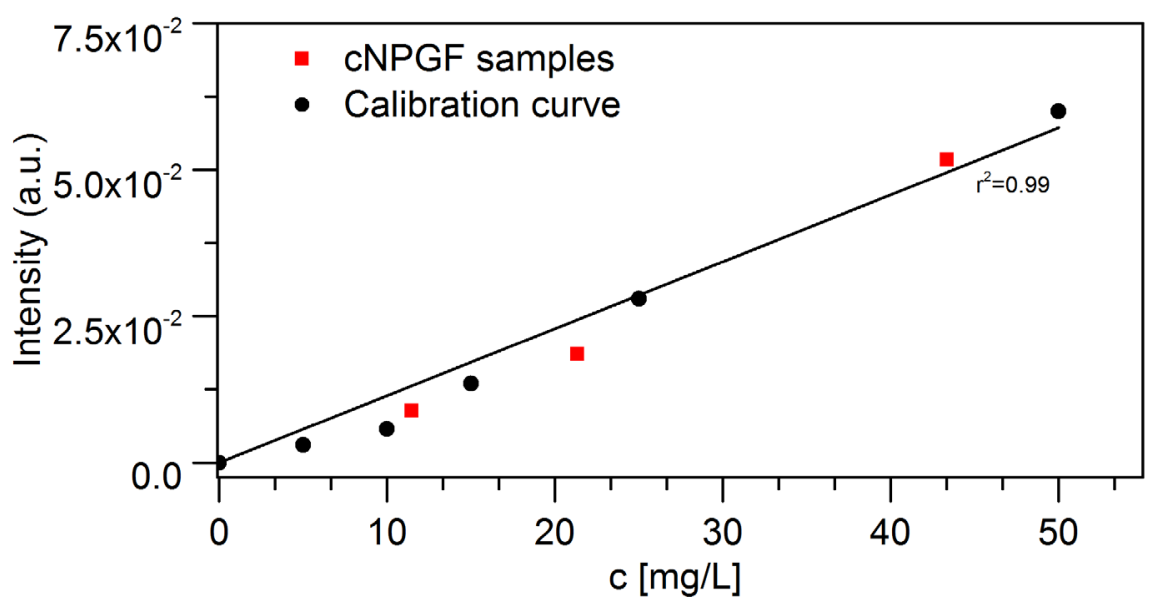

Figure S2. AAS measurements showing the standard curves and the measured samples. 

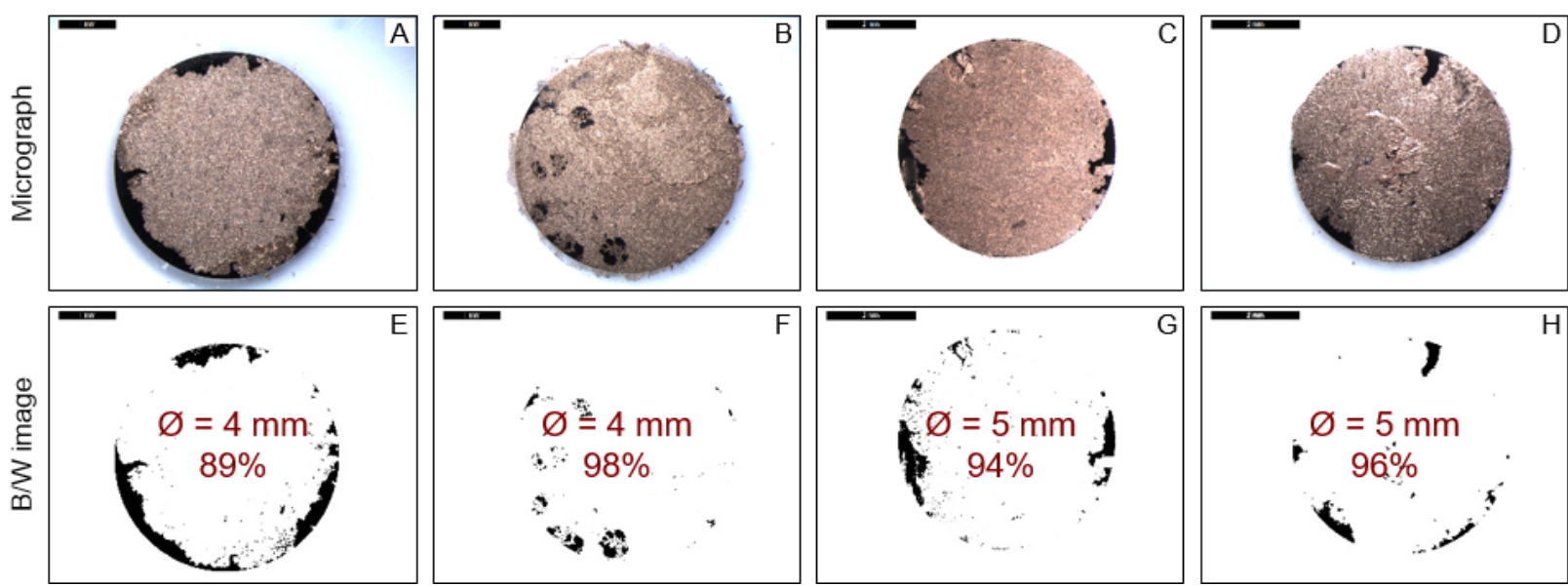

Figure S3. Micrograph images of GC electrodes under an optical microscopy after electrochemical and catalysis testing (A-D) Images processed in software to become black and white, for area determination treatment (E-H). cNPGF coverages of GC area are shown in images.



Figure S4. Cyclic voltammograms of cNPGF film deposited on RDE (A = ca. $\left.0.18 \mathrm{~cm}^{2}\right)$ in $\mathrm{Ar}$-purged (A) $0.10 \mathrm{M} \mathrm{H}_{2} \mathrm{SO}_{4}$ solution recorded at different scan rates, (B) $0.10 \mathrm{M} \mathrm{KOH}$ solution recorded at $20 \mathrm{mV} / \mathrm{s}$ at stationary conditions (black line) and at electrode rotation rate of $1600 \mathrm{rpm}$ (red line). Current densities are normalized per geometrical area of the electrode. 




$20 \mathrm{mM} \mathrm{KCl} / 10 \mathrm{mM} \mathrm{HCl}$

$25 \mathrm{mM} \mathrm{KCl} / 10 \mathrm{mM} \mathrm{HCl}$
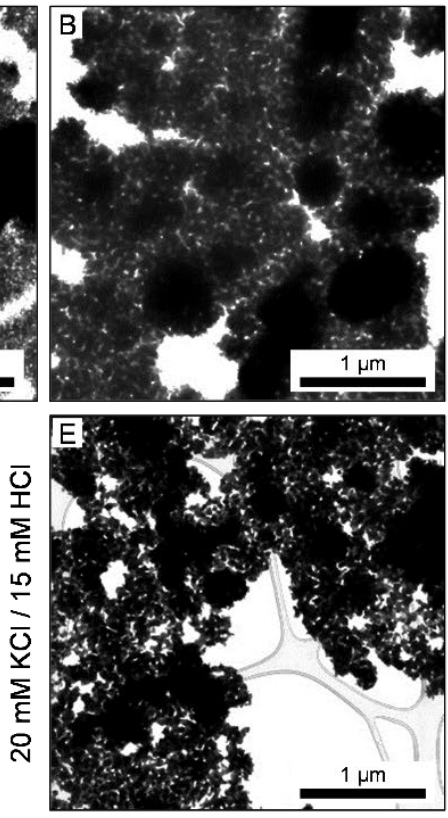

ত̃

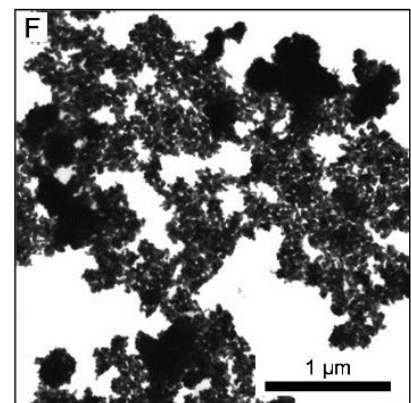

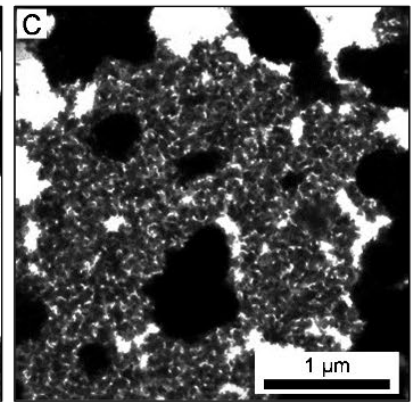

$30 \mathrm{mM} \mathrm{KCl} / 10 \mathrm{mM} \mathrm{HCl}$

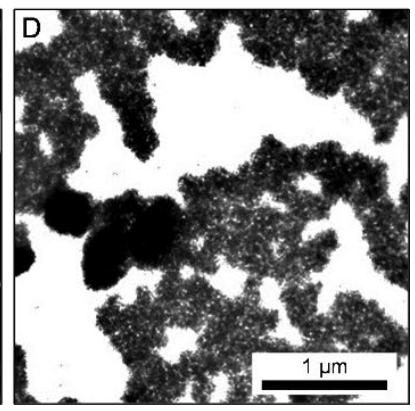

Increasing $[\mathrm{KCl}]$

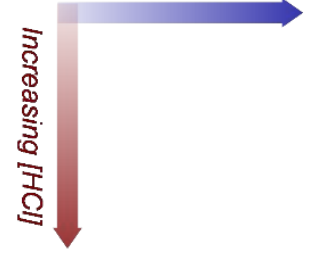

$50 \mathrm{mM} \mathrm{KCl} / 20 \mathrm{mM} \mathrm{HCl}$

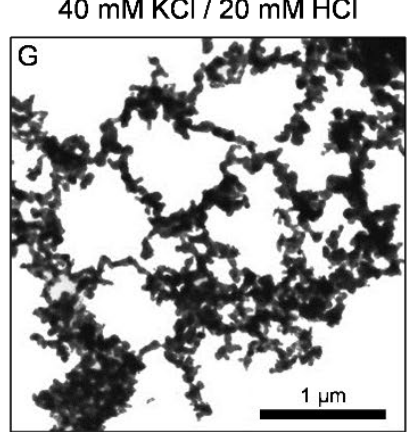

Figure S5. TEM images showing changes of CNPGF in microstructure following changes in both $\mathrm{KCl}$ and $\mathrm{HCl}$ concentrations. Images are all taken with identical magnification, for size comparison. 

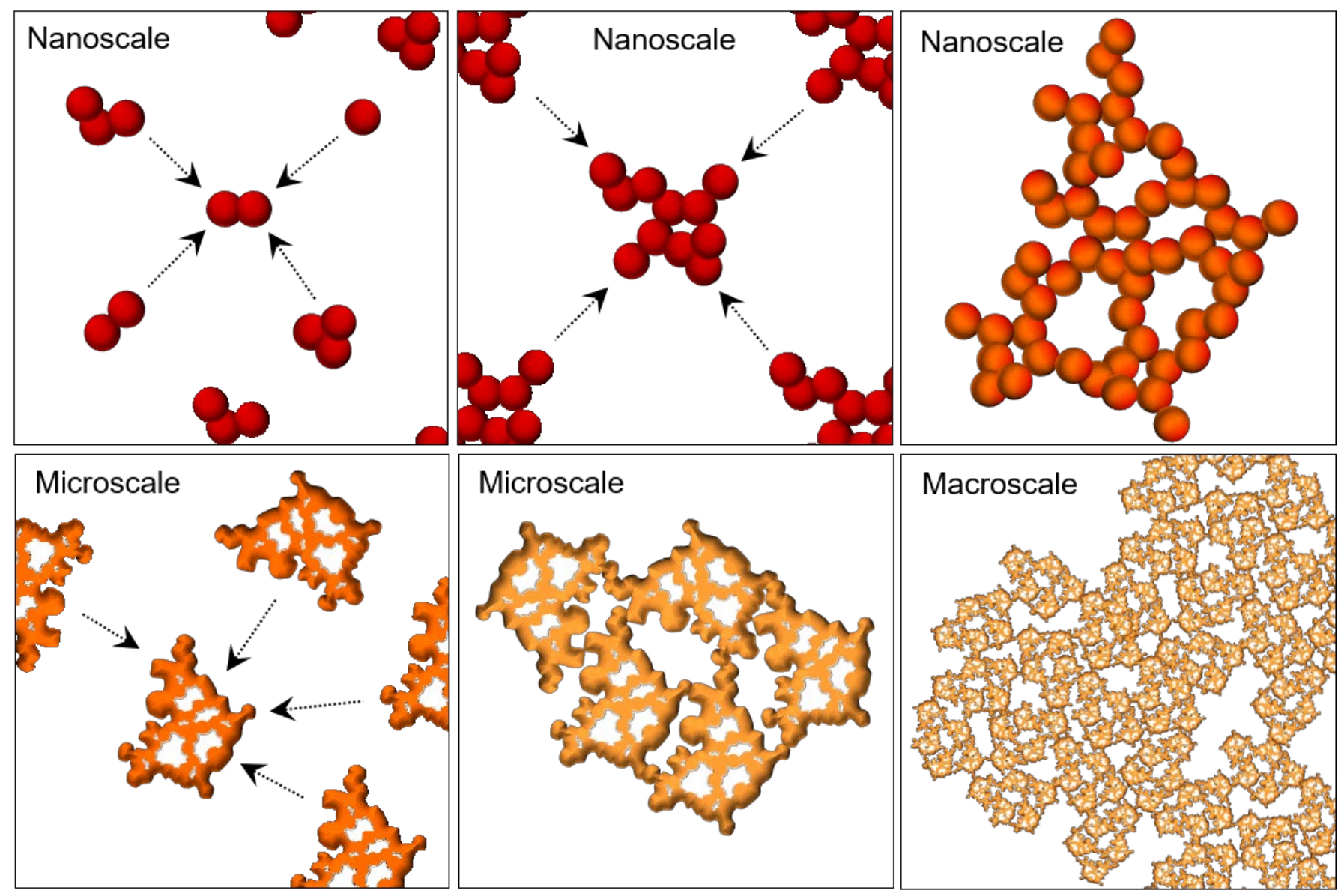

Figure S6. Scheme of cNPGF formation and features evolution from nanoscale to macroscale.

The cNPGF structure has similar nano- and microstructure features (Figures 1B and 1C). This originates from the nature of Au NPs aggregation during the entire cNPGF formation. The cNPGF assembles at the air-liquid interface. The predominantly spherical Au NPs undergo interfacial sorption. When at the interface, Au NP moves in two dimensions and sinters to individual Au NP or cluster of NPs. Due to surface tension forces, synthesis solution evaporation and size of NPs, the sintered nanoscale structure contains fine pores (nm range). As the cNPGF synthesis continues, the nanoscale structures continuously expand by sintering to other nanoscale units. By sintering into larger 2D networks, the microscale features are formed. Due to the nature of material sintering, the nanoscale features are reproduced and maintained within the newly formed microscale structure, resulting in similar morphology observed at two different scales, Figure S6. 


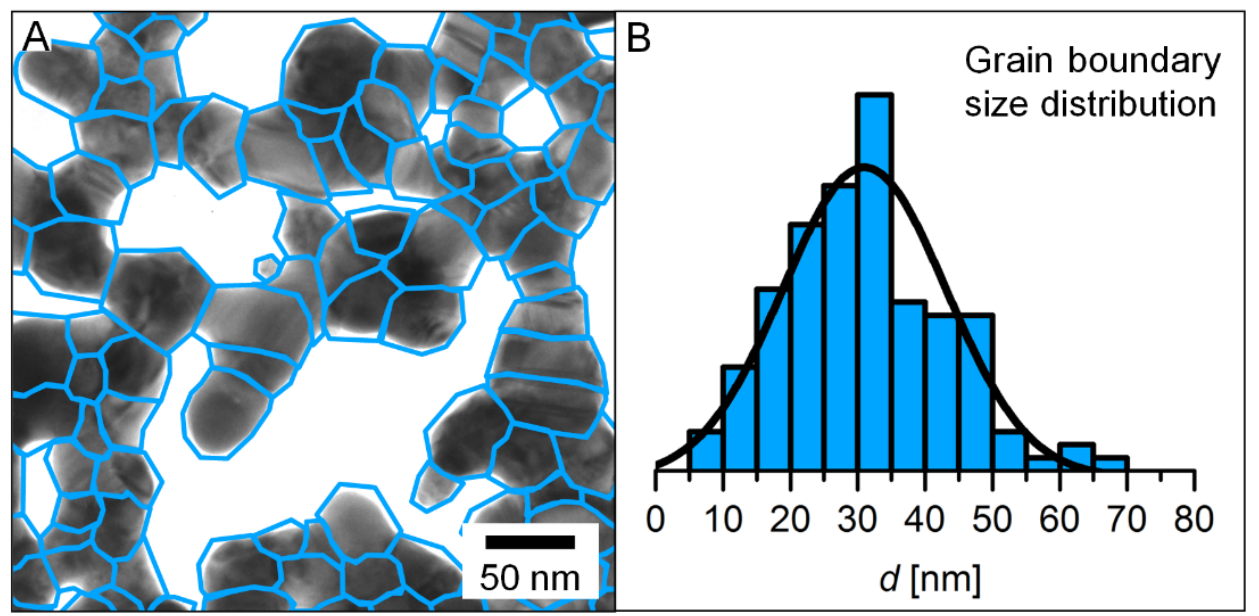

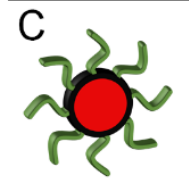

1. AuNP formation

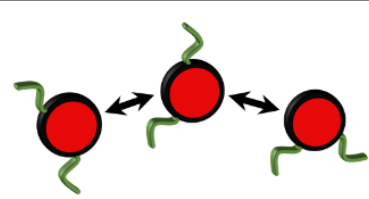

2. MES removal, AuNP migration

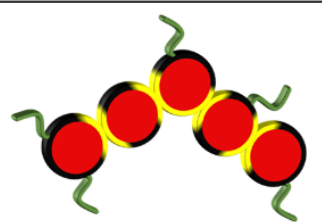

3. Grain boundary formation



4. cNPG film formation

Figure S7. (A) TEM image of cNPGF film with highlighted AuNP boundaries (blue). (B) A AuNP grain boundary size distribution histogram. (C) Scheme of a ligament attachment of individual AuNPs into cNPGF films.
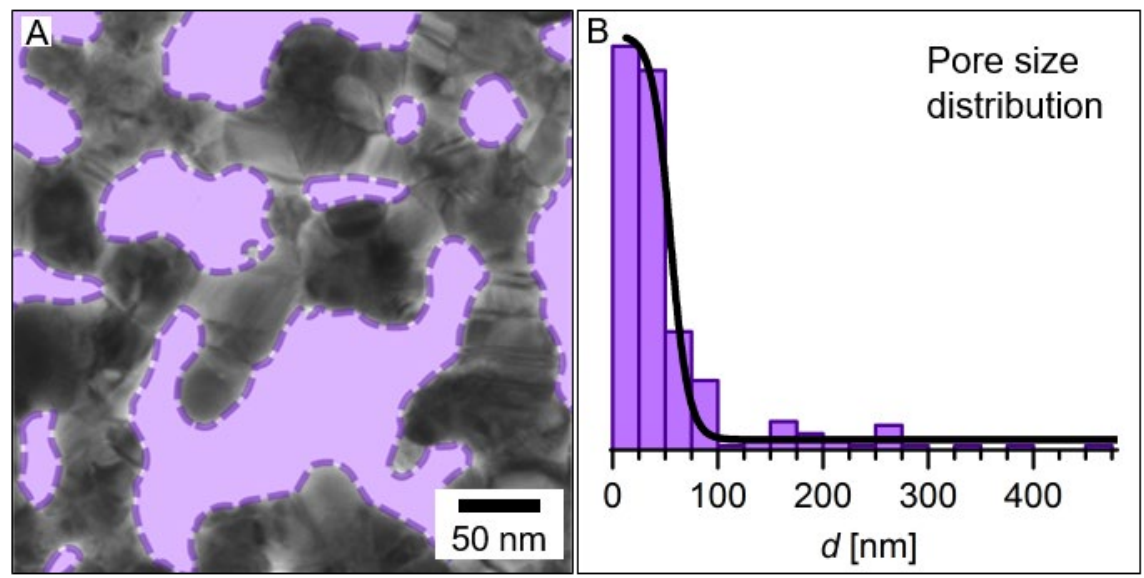

Figure S8. (A) TEM image of cNPGF with highlighted pores (purple) and (B) the corresponding pore size distribution histogram. 
Table S1. The summary of cNPG synthesis parameters, chemical concentrations and experimental observations.

\begin{tabular}{ccc}
\hline Type of additive & Concentration range [mM] & Observed effect \\
\hline $\mathrm{KCl}$ & $10-50$ & $\begin{array}{c}\text { Increased amount of film formation, and } \\
\text { increased ligament thickness }\end{array}$ \\
$\mathrm{HCl}$ & $10-20$ & Larger macropore-to-mesopore ratio \\
$\mathrm{KH}_{2} \mathrm{PO}_{4} / \mathrm{K}_{2} \mathrm{HPO}_{4}(\mathrm{pH} 8.0)$ & $5-25$ & Suppression of film formation \\
$\mathrm{KClO}_{4}$ & $10-25$ & Suppression of film formation \\
\hline
\end{tabular}

